\title{
Mucinous carcinoma of the eyelid with colonic mass: a rare partnership
}

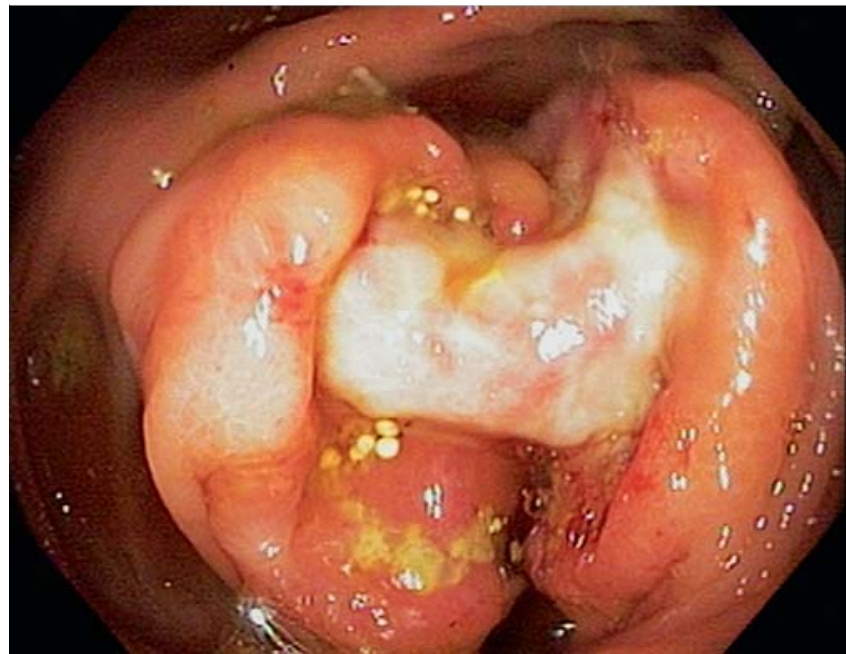

Fig. 1 An ulcerated cecal mass found on colonoscopy, estimated to be $4 \mathrm{~cm}$ in size and occupying most of the cecum.

Mucinous carcinoma of the eyelid is a rare cancer. In medicine, rarely will the diagnosis of one cancer lead to the diagnosis of a second unrelated cancer. However, mucinous carcinoma of the eyelid has been rarely associated with colon cancer [1]. This case demonstrates a very rare occurrence of mucinous carcinoma of the eyelid leading to the diagnosis of sporadic colon cancer.

An 82-year-old man presented to his primary-care physician and was found to have a slow-growing lesion on his right upper eyelid. Subsequently, he was eval- uated by a dermatologist and underwent Mohs surgery. The pathology of the lesion returned a diagnosis of mucinous carcinoma. At that time, given that mucinous carcinoma is most often a secondary carcinoma, a primary cancer was suspected. The patient underwent esophagogastroduodenoscopy (EGD) and colonoscopy. His EGD showed only mild gastric atrophy. His colonoscopy revealed a $4 \mathrm{~cm}$ ulcerated cecal mass occupying most of the cecum ( Fig.1). Pathological analysis of the mass demonstrated a moderately differentiated adenocarcinoma ( Fig.2). Sub- sequently, the patient underwent a right hemicolectomy. Surgical specimens confirmed a moderately differentiated adenocarcinoma with perineural invasion but negative lymph nodes (0/18). After 6 months, the patient is doing well with no recurrence or evidence of distal metastases from either tumor.

Cutaneous mucinous carcinoma is most commonly a secondary lesion rather than a primary carcinoma $[2,3]$. In the case of our patient, the finding of the mucinous carcinoma of the eyelid led to the discovery of a separate and distinct sporadic colonic adenocarcinoma. The occurrence of two separate primary carcinomas, one of them histologically a cutaneous mucinous carcinoma, is incredibly rare. Because this association was known, our patient was treated promptly and now shows no evidence of metastasis of either primary tumor.

Endoscopy_UCTN_Code_CCL_1AD_2AB

\section{Competing interests: None}

\section{Alisha M. Hinds ${ }^{1}$, Dina Ahmad ${ }^{1}$, Kristi T. Lopez ${ }^{1}$, Jason S. L. Holly², Michelle L. Matteson-Kome ${ }^{1}$, Matthew L. Bechtold ${ }^{1}$}

${ }^{1}$ Department of Internal Medicine Gastroenterology, University of Missouri School of Medicine, Columbia, Missouri, USA

2 Department of Anatomical Pathology, University of Missouri School of Medicine, Columbia, Missouri, USA
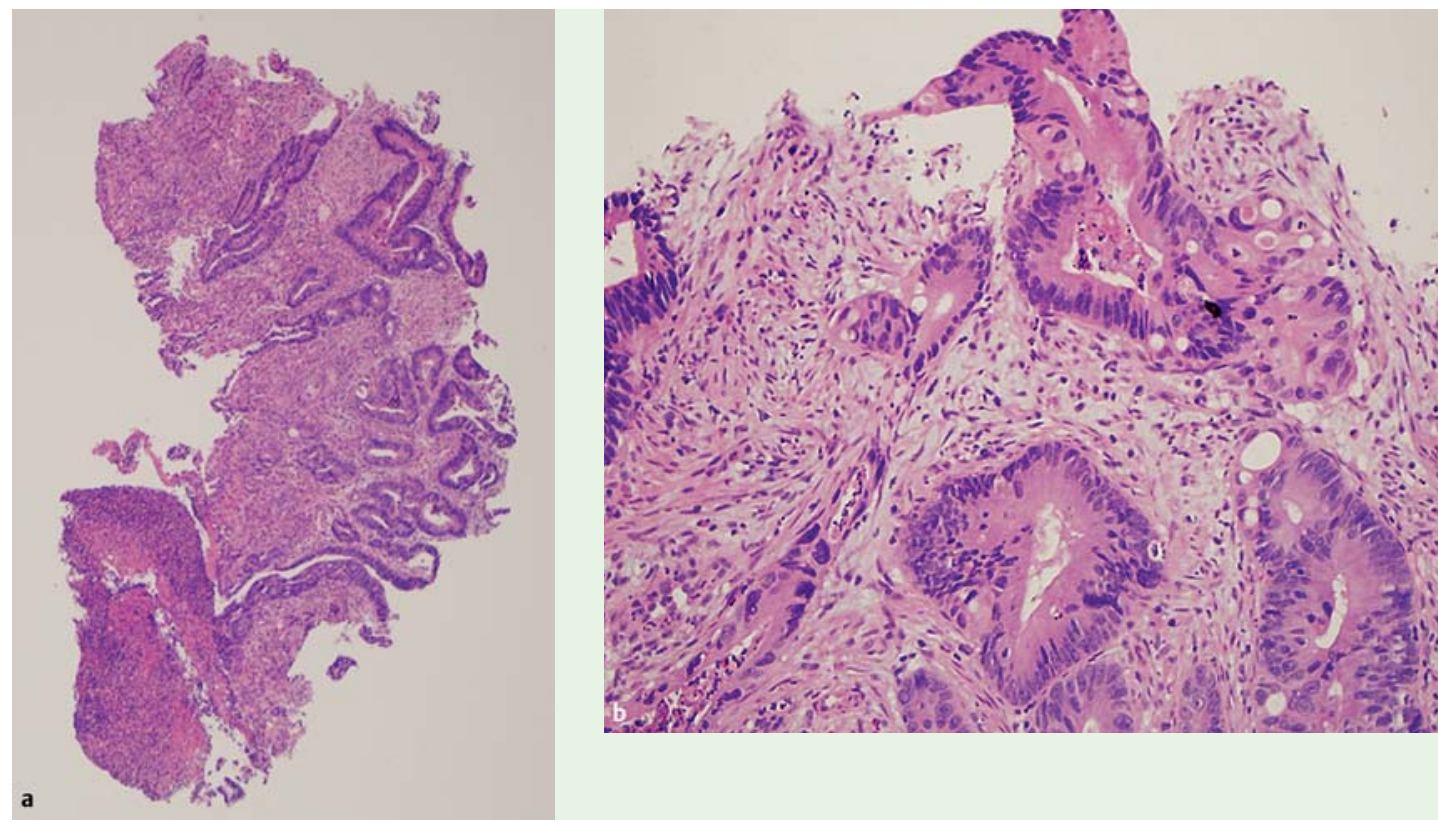

Fig. 2 Colonic mucosa with an invasive adenocarcinoma comprised of malignant cells occurring in singleton and in incomplete glands with surrounding desmoplastic response. H\&E stain, magnification $4 \times(a), 20 \times(b)$. 


\section{References}

1 Agiannidis C, Pana ZD, Molyva D et al. Metachronous occurrence of colorectal cancer in a Muir-Torre syndrome patient presenting with recurrent sebaceous adenoma of the eyelid: case report and updated review of the literature. J Cutan Med Surg 2012; 16: 394-399

2 Mardi K, Diwana VK. Primary cutaneous mucinous carcinoma: a rare entity. Indian Dermatol Online J 2011; 2: 82 -84

3 Bansal R, Patel T, Sarin J et al. Cutaneous and subcutaneous metastases from internal malignancies: an analysis of cases diagnosed by fine needle aspiration. Diagn Cytopathol 2011; 39: $882-887$

\section{Bibliography}

DOI http://dx.doi.org/

10.1055/s-0033-1359239

Endoscopy 2014; 46: E107-E108

(C) Georg Thieme Verlag KG

Stuttgart · New York

ISSN 0013-726X
Corresponding author

Matthew L. Bechtold, MD, FACG

Division of Gastroenterology

Five Hospital Drive, CE405

Columbia, MO 65212

United States of America

Fax: +1-573-884-4595

bechtoldm@health.missouri.edu 